\title{
Active deformation of dielectric elastomer for detection of biofouling
}

\author{
Krpovic, Sara; Dam-Johansen, Kim; Skov, Anne Ladegaard; Rosset, Samuel; Anderson, lain
}

Published in:

Electroactive Polymer Actuators and Devices (EAPAD) XXII

Link to article, DOI:

$10.1117 / 12.2558402$

Publication date:

2020

Document Version

Publisher's PDF, also known as Version of record

Link back to DTU Orbit

Citation (APA):

Krpovic, S., Dam-Johansen, K., Skov, A. L., Rosset, S., \& Anderson, I. (2020). Active deformation of dielectric elastomer for detection of biofouling. In Y. Bar-Cohen, I. A. Anderson, \& H. R. Shea (Eds.), Electroactive Polymer Actuators and Devices (EAPAD) XXII [1137521] SPIE - International Society for Optical Engineering. Proceedings of SPIE - The International Society for Optical Engineering Vol. 11375 https://doi.org/10.1117/12.2558402

\section{General rights}

Copyright and moral rights for the publications made accessible in the public portal are retained by the authors and/or other copyright owners and it is a condition of accessing publications that users recognise and abide by the legal requirements associated with these rights.

- Users may download and print one copy of any publication from the public portal for the purpose of private study or research.

- You may not further distribute the material or use it for any profit-making activity or commercial gain

- You may freely distribute the URL identifying the publication in the public portal 


\section{Active deformation of dielectric elastomer for detection of biofouling}

Krpovic, Sara, Dam-Johansen, Kim, Ladegaard Skov, Anne, Rosset, Samuel, Anderson, lain

Sara Krpovic, Kim Dam-Johansen, Anne Ladegaard Skov, Samuel Rosset, lain Anderson, "Active deformation of dielectric elastomer for detection of biofouling," Proc. SPIE 11375, Electroactive Polymer Actuators and Devices (EAPAD) XXII, 1137521 (22 April 2020); doi: 10.1117/12.2558402

Event: SPIE Smart Structures + Nondestructive Evaluation, 2020, Online Only, California, United States 


\title{
Active deformation of dielectric elastomer for detection of biofouling
}

\author{
Sara Krpovic ${ }^{1,2,3}$, Kim Dam-Johansen ${ }^{1}$, Anne Ladegaard Skov ${ }^{2}$, Samuel Rosset ${ }^{3}$, Iain Anderson ${ }^{3}$ \\ ${ }^{1}$ Technical University of Denmark, Department of Chemical and Biochemical Engineering, CoaST, \\ Kgs. Lyngby 2800, DK \\ ${ }^{2}$ Technical University of Denmark, Department of Chemical and Biochemical Engineering, Danish \\ Polymer Centre, Kgs. Lyngby 2800, DK \\ ${ }^{3}$ The University of Auckland, Auckland Bioengineering Institute, Biomimetics Laboratory, \\ Auckland 1010, NZ
}

\begin{abstract}
Biofouling accumulation on synthetic underwater surfaces presents serious economic problem for the marine industry. When a substrate-bonded dielectric elastomer (DE) is subjected to high voltage, deformations in form of creases can be formed at the surface of the DE. This deformation, has been already demonstrated for the prevention and detachment of biofouling from the surface of DEs. In this work, we add sensing capability to the anti-biofouling effect of active DE surfaces. A device consisting of a metallic plate, a Kapton sheet, and a thin silicone membrane is immersed in conductive solution, which acts as one electrode, with the metal plate being the second electrode. Two different conductive solutions were used $3.5 \mathrm{wt} \% \mathrm{NaCl}$ and $20 \mathrm{wt} \% \mathrm{NaCl}$. The surface deformation of the silicone as a function of applied voltage is monitored under microscope in order to verify electrical measurements. Breakdown measurements of the dielectric material in different conductive solutions are also performed. Because the membrane is made from incompressible elastomer and bonded to a rigid substrate, voltages below the creasing threshold create no deformation in the membrane, and therefore no change in capacitance. Above the voltage threshold, creasing instabilities appear at the surface of the silicone, thus increasing the capacitance of the device. Therefore, the capacitance of the sensor is measured as a function of applied voltage, and the voltage at which the capacitance increases is the threshold voltage at which creases occur. Creases are identified when using both $3.5 \mathrm{wt} \% \mathrm{NaCl}$ and $20 \mathrm{wt} \% \mathrm{NaCl}$ as top electrode. Theoretical values of creasing voltage deviate from the experimental measurements. Type of conductive solution is shown to have no significant influence on a breakdown voltage.
\end{abstract}

Keywords: dielectric elastomer, sensor, creasing, biofouling.

\section{Introduction}

Marine biofouling presents unwanted accumulation of biological organisms (bacteria, sponges, tubeworms, algae, mussels etc.) on surfaces which are exposed to natural aqueous environment (eg. ships and vessels, oil and wind-turbine seaplatforms). ${ }^{1}$ Increased costs related to transport delays, high fuel consumption, hull maintenance and repair, frequent cleaning of marine surfaces, are consequence of limited performance of devices, materials and underwater structures covered with biofouling. ${ }^{1-3}$ Greenhouse gas emission ${ }^{4,5}$, spreading of non-native biofouling species ${ }^{6}$ all over the world and then development of antifouling coatings, which implied use of toxic ingredients for coating formulation and in that way caused extinction of certain biofouling species, are some of the environmental concerns ${ }^{7}$ caused by biofouling. Therefore, this natural phenomenon presents a major economic and ecological problem for the marine industry. Hence, in the last few decades, efforts have been put into development of efficient, ecologically and economically friendly antifouling technologies. Currently used antifouling strategies may be divided into two types: biocide-release-based antifouling coatings and non-biocide-release-based antifouling coatings. ${ }^{1,8}$ Biocide-release-based antifouling coatings release biocides, which kill biological organisms and in that way restrain biofouling attachment. On the other hand, non-biociderelease-based antifouling coatings significantly reduce the adhesion strength of biofouling species to the surface causing that biofoulants are easily removed by simple mechanical cleaning or just by movement of the ship through the water. ${ }^{8}$ Most commonly used commercial coatings which reduce adhesion of biofouling to the surface are mainly made of silicone elastomers ${ }^{5,6}$, due to their low surface energy and high smoothness. 
In contrast to previously described antifouling strategies, in recent years new solutions to prevent biofouling have been proposed. Some of these new approaches are inspired by nature, and they offer biofouling control through permanent nano and micro-topography modification. ${ }^{6,9}$ One of the examples is biomimicry ${ }^{6,10}$ of the antifouling mechanism of shark skin. ${ }^{2,6,7}$ As a result of the riblet microtexture of the shark's skin and the mucous layer, biofoulants do not attach to the shark. Even though these approaches have potential for further development, they do have disadvantages, such as: nature's complex design is not easy to copy on the macroscale, the fabrication process is somewhat complicated and may not lead to the required homogeneity, and patterned coatings are not suitable for harsh aqueous environments. ${ }^{8}$

Other antifouling approaches have been inspired by methods used in soft-robotics systems based of dielectric elastomers (DEs). Wang et $\mathrm{al}^{11}$ proposed that creasing instabilities, which occur at the top surface of substrate bonded DE under applied voltages, if rationally controlled, can be potentially used for different applications, among which is active control of biofouling. Studies were first performed to fundamentally understand and control instabilities of soft dielectrics under various working conditions in order to be used for desired applications. ${ }^{11-17}$ Then, it has been demonstrated that the deformation of substrate bonded elastomer surfaces under applied voltages can detach different biofoulingspecies. ${ }^{8,12,18}$ Fabrication of the dynamic surfaces over large areas through simple and practical processes is the advantage of this approach, which is stimulating further research in this direction. Therefore, building on this technology, it is of great interest to add the capability of detecting presence of biofouling and measuring the efficiency of DE-based antifouling. In this work we present an experimental method to directly detect creasing instabilities at the surface of the substrate bonded $\mathrm{DE}$, which is a first step in making a sensor for monitoring the growth of biofouling. Since creasing instabilities appear at a well-defined voltage that depends on the mechanical stiffness of the active layer, the modification of the stiffness caused by the attachment of biofoulants will be detected by an increase of the threshold voltage at which creases appear.

Key innovation of our idea is that to the DE actuator with a creasing deformation, we add self-sensing capability. When a substrate-bonded DE is subjected to high voltage, deformations in form of creases can be formed at the surface of the DE. A device consisting of metal surface, which could be metal surface of the ship or some other offshore structure, a thin silicone elastomer (silicone coating on the surface of the ship), is immersed in salty water (sea water), which acts as one electrode, with the metal surface being the second electrode. This structure forms a device which acts as an capacitor. Throughout the article the term "sensor" will refer to the capacitor. Under applied voltage, the surface of the DE is initially in a flat state without deformation. However, when critical voltage is reached DE starts to deform in a pattern of creases. By measuring capacitance of the sensor as a function of applied voltage, the threshold voltage at which creases occur when there is an increase of capacitance is identified. Because the DE is bonded to a rigid metal substrate, and because elastomers are incompressible, voltages below the creasing threshold create no deformation at the top surface of the DE, and therefore no change in capacitance. However, formation of creases increases the capacitance of the sensor. Attachment of the stiff biofouling material to the surface of the silicone elastomer, causes the change of the surface stiffness of the silicone elastomer. Due to this change, the threshold voltage necessary to develop the creases at the surface of the silicone increases. Measuring the capacitance versus applied voltage enables to identify the voltage threshold, and therefore monitor biofouling growth.

Experiments are conducted with a simple structure - a soft commercial silicone (Elastosil 00-30), on one side bonded to the stiff substrate (Kapton tape bonded to metal plate), and on other side immersed to conductive solution. Electrical measurements are performed and method is developed to detect creasing deformation at the top surface of a DE, as a first part of the proposed idea of the actuator with self-sensing capability. Since, critical electric field, $E_{\text {critical }}$, for the electrocreasing instability of the elastomer, can be expressed by using the equation ${ }^{19}$ :

$$
E_{\text {critical }} \approx 1.03 \sqrt{\mu_{e} / \varepsilon_{e}{ }^{\prime} \varepsilon_{0}}
$$

where $\mu_{e}$ and $\varepsilon_{e}{ }^{\prime}$ are the shear modulus and relative permittivity of the silicone elastomer, and $\varepsilon_{0}=8.85 \mathrm{e}-12 \mathrm{~F} / \mathrm{m}$ is the vacuum permittivity. And since, the magnitude of the applied electrical field can be also expressed as ${ }^{16}$ :

$$
E_{\text {critical }}=\frac{V_{\text {critical }}}{\left(t_{e}+t_{k} \frac{\varepsilon_{e}^{\prime}}{\varepsilon_{k}^{\prime}}\right)}
$$

Where $V_{\text {critical }}$ is the applied creasing voltage and, $\varepsilon_{e}{ }^{\prime}$ and $\varepsilon_{k}{ }^{\prime}$ are the relative permittivities of the DE and Kapton tape, and $t_{e}$ and $t_{k}$ are the thicknesses of the DE and Kapton tape, respectively. Theoretical calculations of the critical voltage are determined using equations (1) and (2), and compared with experimental values obtained from electrical measurements. 


\section{Experimental}

Instabilities of soft dielectrics under applied voltage sometimes lead to breakdown of the DE before creasing instabilities occur. ${ }^{20,21}$ In order to demonstrate that the salinity of the liquid electrode does not influence the breakdown of the DE, breakdown voltage measurements are performed with four different conductive solution used as top electrode (tap water, $3.5 \mathrm{wt} \% \mathrm{NaCl}, 10 \mathrm{wt} \%$ and $20 \mathrm{wt} \% \mathrm{NaCl}$ solutions). Breakdown voltage of commercial silicone film (Elastosil 2030,

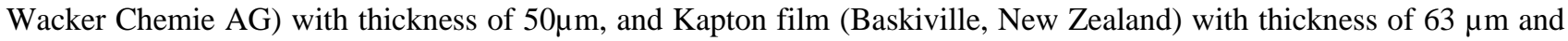
commercial silicone film bonded together, is measured in above mentioned solutions. Films are on one side bonded on to a copper substrate, while on the top surface films are immersed in different conductive solutions (tap water, $3.5 \mathrm{wt} \% \mathrm{NaCl}$, $10 \mathrm{wt} \%$ and $20 \mathrm{wt} \% \mathrm{NaCl}$ solutions). A voltage is applied between conductive solution and copper plate, until electrical breakdown occurs, or until voltage reaches $9500 \mathrm{~V}$, which is close to instrumentation limit. Since measured breakdown voltage values of DE films are quite stochastic due to different factors such as presence of dust particles or other defects in the DE film, it is necessary to perform large number of tests in order to obtain a reasonable average value of the breakdown voltage. ${ }^{17}$ Therefore, the measurements of the breakdown voltage are repeated 20 times.

It has been reported in the literature that Kapton film is used as protective layer, ${ }^{16}$ which prevents the electric field in the deformed DE to become excessively high and causes electrical breakdown before creases appear. Therefore, in this study, a rigid polyimide tape, Kapton, with a thickness of $63.5 \mu \mathrm{m}$, and relative permittivity of 3.4 is also used as protective layer in the sensor. Elastosil 2030 silicone film, with precise thickness of $50 \mu \mathrm{m}$, relative permittivity of $2.8^{22}$ and calculated shear modulus of approximately $393 \mathrm{KPa}^{23}$, is first considered to be used in the sensor. Theoretical value of the voltage necessary to produce the creases at the top surface of the Elastosil 2030 film, bonded to the Kapton tape, is approximately $13.3 \mathrm{kV}$. Even though use of Elastosil $2030 \mathrm{film}$ is convenient because it is already made and has a precise thickness, the equipment limit is much lower $(5000 \mathrm{~V})$ than calculated value of the onset voltage, and therefore, eliminates the use of Elastosil 2030 in in the creasing experiments. Hence our choice is much softer silicone elastomer Ecoflex 00-30.

Ecoflex 00-30, two-parts (A and B) commercial Pt-curing silicone elastomer is used as a dielectric material in the sensor. Silicone elastomer is obtained from FormX, Australia. Parts A and B are weighed according to the manufacturer's recommended mixing ratio 1:1 (part A: part B) and mixed in a speed mixer (Thinky Mixer ARE-250) for 2 minutes with $2000 \mathrm{rpm}$. The corresponding shear modulus for this mixing ratio is found to be $20 \mathrm{KPa},{ }^{24}$ while relative permittivity is 3.4. ${ }^{23}$ To make films, mixture is then blade casted on poly(methyl methacrylate) (PMMA) support sheet. Silicone films, of around $400 \mathrm{~cm}^{2}$ in area, are prepared. Blade gap of $100 \mu \mathrm{m}$ is used in order to obtain an approximately $50 \mu \mathrm{m}$ thick films after curing. Silicone films are cured at $80^{\circ} \mathrm{C}$ for 2 hours, which ensures that silicone is fully cured. Post-curing of the silicone films was not deemed necessary. ${ }^{25}$ After curing, samples of around $20 \mathrm{~cm}^{2}$ are cut and used to make sensors. All samples have different thickness ( $50 \mu \mathrm{m} \pm 25 \mu \mathrm{m}$ ). Since samples are cut from different parts of the silicone sheet, this could be the cause of the large variation in the sample thickness. The sample thickness is determined using optical microscope after electrical measurements are performed, or after electrical breakdown in the sample occurred. Since silicone is bonded to Kapton tape and electrical measurements are performed first, this could have an influence on sample thickness and cause uncertainties in thickness measurements.

The schematic illustration of the sensor is presented in Figure 1. A rigid polyimide tape, Kapton, is bonded on a metal plate. Prepared silicone elastomer, Ecoflex 00-30 is then transferred from PMMA support sheet on the Kapton film. Ecoflex 00-30 film is then immersed in a transparent conductive solution, which acts as an electrode, with the metal plate being second electrode.

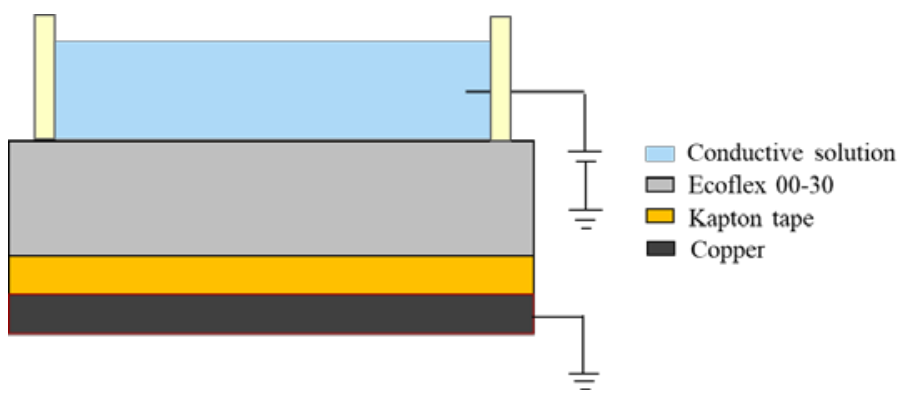

Figure 1. Schematic illustration of the sensor. On the top surface of the $\overline{\mathrm{D}} \mathrm{E}$ creasing instabilities are produced and measured. 
Two conductive solutions with $3.5 \mathrm{wt} \%$ and $20 \mathrm{wt} \%$ of $\mathrm{NaCl}$ are prepared. The $3.5 \mathrm{wt} \%$ is the preferred amount of salt in the solution, due to the fact that same amount of salt is to be found in sea water, while $20 \mathrm{wt} \% \mathrm{of} \mathrm{NaCl}$ is amount of salt reported in the literature when studying creasing deformation of DEs. Transparency of conductive solutions enables the monitoring of the silicone surface deformation under microscope as a function of the applied voltage, which is a first method for detection of creases reported in the literature. In this case, visual detection of creases appearance at certain voltage is used for verification of electrical measurements. The sensor, which acts as a capacitor, C, is connected in series with a $50 \mathrm{M} \Omega$ resistor, R. This forms an RC circuit, which is connected to a high voltage power supply (Trek 610E, USA). A square wave voltage is applied to the RC circuit and the sensor / capacitor charges and discharges with the voltage applied. Schematic illustration of RC circuit connected to square wave voltage source is presented in Figure 2.

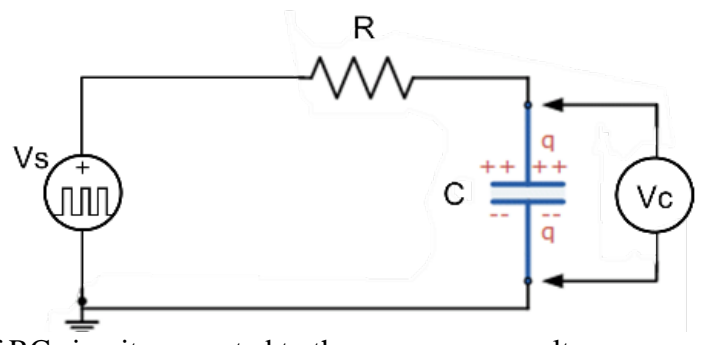

Figure 2. Schematic illustration of RC circuit connected to the square wave voltage source, Vs.

Voltage across the capacitor, Vc, is measured when a square wave voltage (at the frequency of $1 \mathrm{~Hz}$ ) is applied to the RC circuit, in order to calculate capacitance, of the sensor. Measured voltage across the capacitor is plotted as a function of time. Time constant values are calculated by extrapolating the initial slope of the charging curve with a straight line until it intersects the final voltage level over the capacitor. With obtained value of the time constant and known resistance of the resistor in the RC circuit, capacitance of the charging capacitor is calculated. All capacitance values are reported as means of five measurements.

\section{Results and Discussion}

\subsection{Breakdown instabilities}

Breakdown voltages of $50 \mu \mathrm{m}$ thick Elastosil 2030, as well as $50 \mu \mathrm{m}$ thick Elastosil 2030 and $63 \mu \mathrm{m}$ thick Kapton tape bonded together, in different conductive solutions are presented in Figure 3.

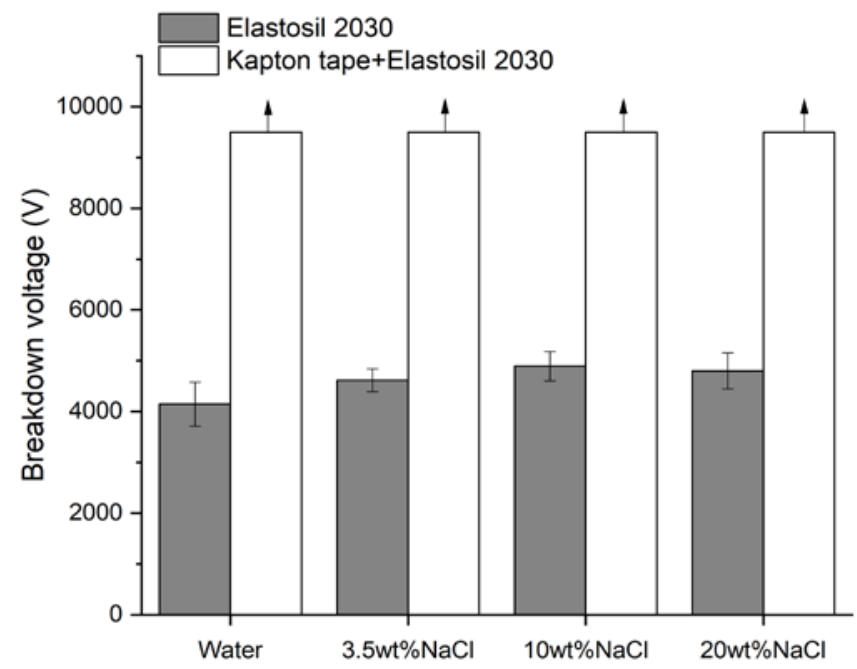

Figure 3. Breakdown voltages of $50 \mu \mathrm{m}$ thick Elastosil 2030 (grey columns) and $50 \mu \mathrm{m}$ thick Elastosil 2030 and $63 \mu \mathrm{m}$ thick Kapton tape bonded together (white columns), in different conductive solutions. Arrow indicates higher breakdown voltage than value stated. Breakdown voltage above $9500 \mathrm{~V}$ could not be detected due to instrumentation limit. 
Data indicates that the breakdown voltages of Elastosil 2030 across all tested solutions are similar. In case of Elastosil 2030 and Kapton tape bonded together in most of measurements, within tested voltage range (0-9500 V), breakdown is not detected. However, here it should be noted that in 3 out of 20 measurements with water, breakdown occurred at voltage just below $9500 \mathrm{~V}$. Lower breakdown voltage is also noted in 14 out of 20 measurements with $3.5 \mathrm{wt} \% \mathrm{NaCl}$ solution, and in 5 out of 20 measurements with $10 \mathrm{wt} \% \mathrm{NaCl}$ solution. Only when using $20 \mathrm{wt} \% \mathrm{NaCl}$ solution, breakdown was not detected in any of the performed measurements in the tested breakdown range. Results obtained for Elastosil 2030 indicate that type of the liquid electrode has no influence on the breakdown voltage. Breakdown voltages for Kapton tape and Elastosil 2030 bonded together are higher than for Elastosil 2030 alone, as expected.

\subsection{Creasing instabilities}

Initially the surface of the membrane is in a flat and smooth state without any observed deformation (Figure 4A). However, when a certain voltage is reached, surface of the DE suddenly starts to deform in a pattern of creases as shown in Figure 4B.

A)

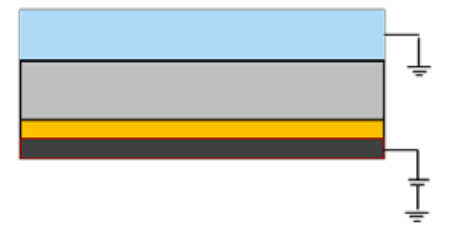

B)

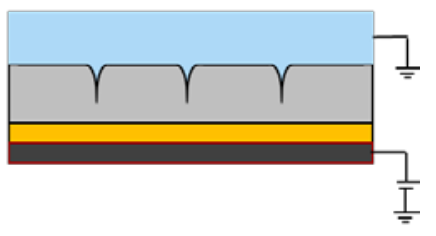

Kapton tape

$\square$ Copper plate

Figure 4. Schematic illustration of the sensor when surface of the dielectric elastomer is in (A) flat state and in (B) creased state.

Capacitance as function of applied voltage, of sensors where top electrode is $3.5 \mathrm{wt} \% \mathrm{NaCl}$ and $20 \mathrm{wt} \% \mathrm{NaCl}$, is presented in Figure 5A and 5B, respectively.

A)

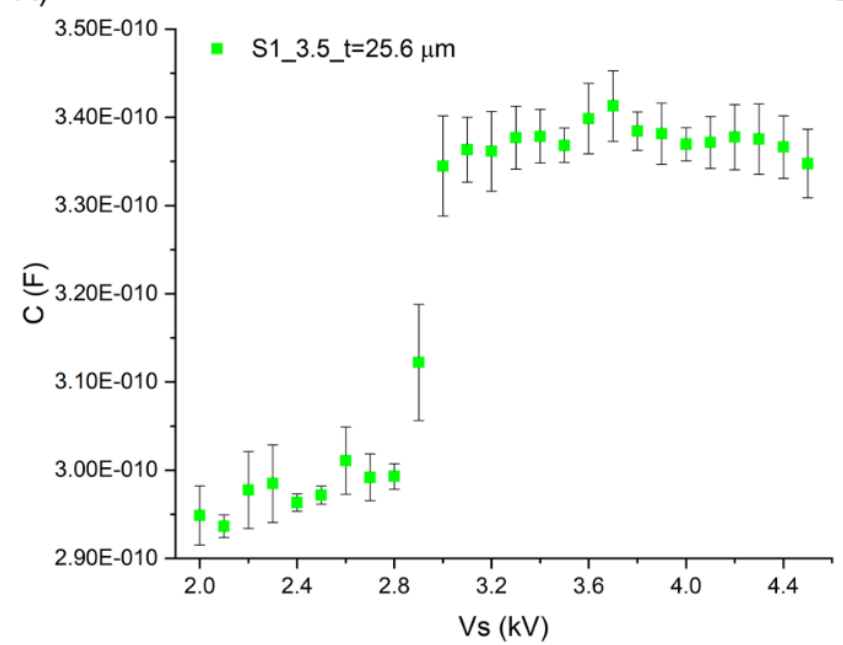

B)

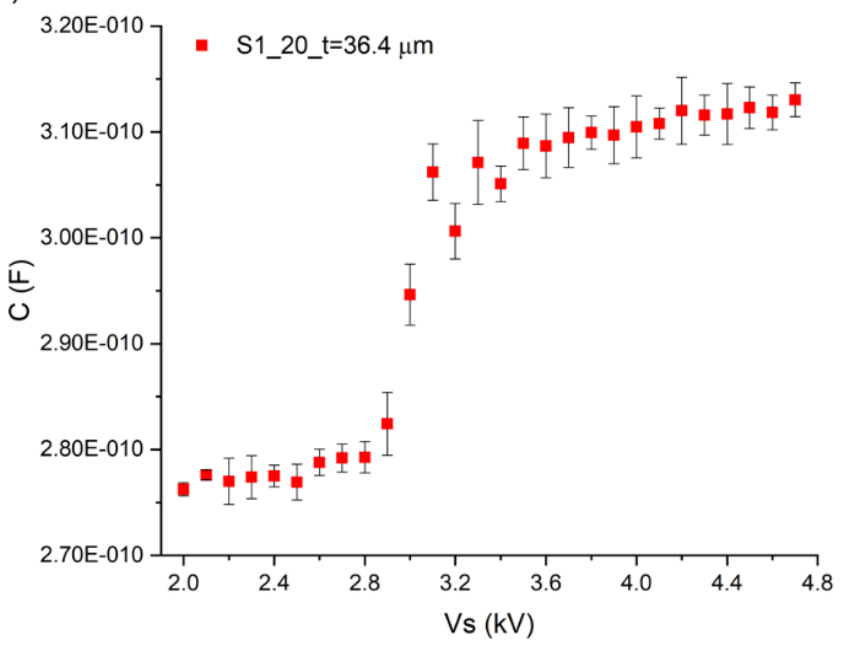

Figure 5. Capacitance as a function of applied voltage of the sensors with creasing voltage at (A) $2.9 \mathrm{kV}$, thickness of DE $25.6 \mu \mathrm{m}$ and top electrode $3.5 \mathrm{wt} \% \mathrm{NaCl}$ solution and (B) $3 \mathrm{kV}$, thickness of DE $36.4 \mu \mathrm{m}$ and top electrode $20 \mathrm{wt} \% \mathrm{NaCl}$ solution.

Creasing voltage is detected as onset voltage at which creases occur, and there is change of capacitance. Creases are detected with both conductive solutions used as top electrode. In Figure 5A, it can be seen that for the sensor with thickness of Ecoflex 00-30 of $25.6 \mu \mathrm{m}$ and top electrode $3.5 \mathrm{wt} \% \mathrm{NaCL}$, creasing voltage is $2.9 \mathrm{kV}$, while from Figure $5 \mathrm{~B}$ it can be seen that for the sensor with thickness of Ecoflex 00-30 of 36.4 $\mu \mathrm{m}$ and top electrode $20 \mathrm{wt} \% \mathrm{NaCL}$, the creasing voltage is $3 \mathrm{kV}$. Creases at the top surface are also visually observed at these voltages (video in Supplementary material). Because 
the membrane is bonded to a rigid substrate, and because elastomers are incompressible, voltages below the creasing threshold create no deformation in the membrane, and therefore no change in the capacitance. However, the formation of creases at the onset voltage increases the capacitance of the device. It should be noted that creasing instabilities are not seen and measured in all sensors. However, all samples where creasing deformation is visually observed, also show capacitance increase at the creasing voltage.

By combining equations (1) and (2), we can predict onset voltage at which creasing instabilities occur. Experimentally detected and theoretically predicted critical voltage for sensors with different thickness of Ecoflex 00-30, with $3.5 \mathrm{wt} \%$ $\mathrm{NaCl}$ and $20 \mathrm{wt} \% \mathrm{NaCl}$ conductive solutions as top electrode are presented in Figure 6A and 6B, respectively.

A)

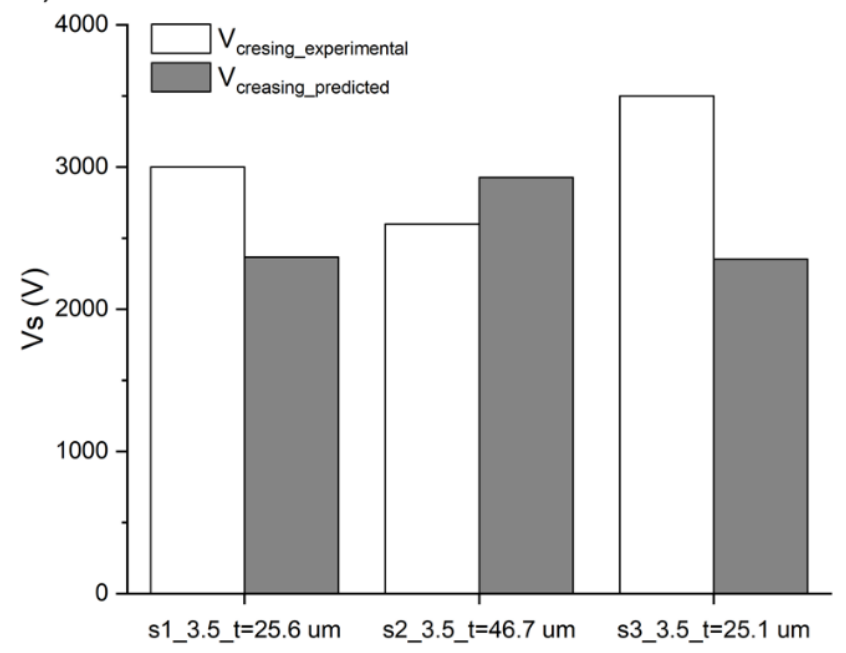

B)

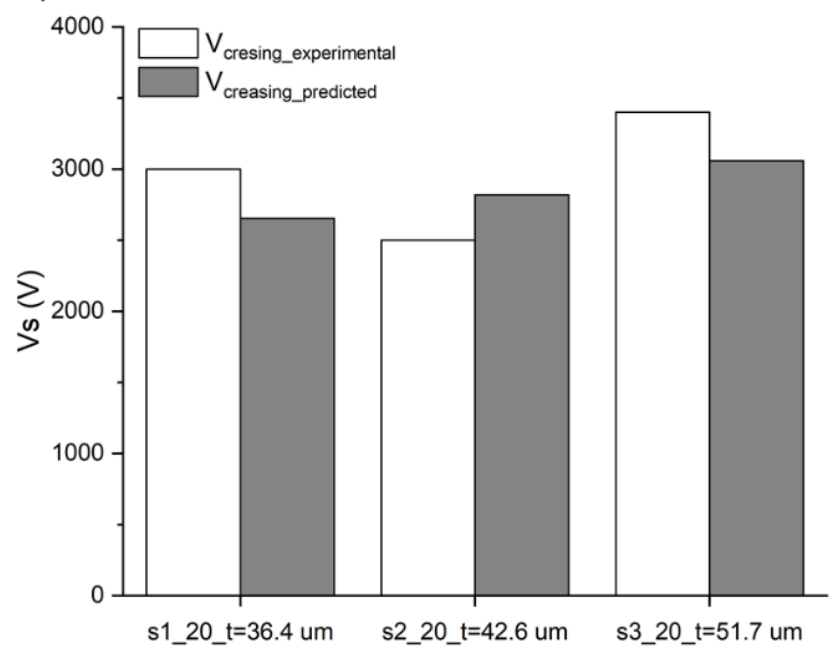

Figure 6. Experimentally detected creasing voltage (electrical measurements and visual conformation) and theoretical prediction of the creasing voltage for sensors with different thickness of DE and (A) $3.5 \mathrm{wt} \% \mathrm{NaCl}$ and (B) $20 \mathrm{wt} \% \mathrm{NaCl}$ solution as top electrode.

Data indicates difference between theoretical and experimental values of creasing voltage. This difference between experimental and theoretical values is higher in case of the sensors with $3.5 \mathrm{wt} \% \mathrm{NaCl}$ (Figure 6A). Theoretical calculations show increase of the creasing voltage with the thickness of the DE. However, this trend in is not experimentally confirmed in our study. The reasons for the significant difference between theoretical predictions and experimentally obtained values of the creasing voltage, may be due to the uncertainty in the theoretical calculations which are caused by deviations in values of thickness, dielectric permittivity and shear modulus of Ecoflex 00-30 and Kapton tape. However, the difference between the predicted creasing voltage and effective creasing voltage does not present a problem for the proposed method, since our aim is to detect the change of the onset voltage over time.

\section{Conclusion and outlook}

We report the voltage-induced creasing instability in dielectric elastomer membrane bonded on a rigid substrate in two different conductive solutions used as top electrode. In order to verify whether conductive solution could have influence on breakdown of the DE, breakdown measurements are first performed in different conductive solutions (tap water, 3.5 wt $\% \mathrm{NaCl}, 10 \mathrm{wt} \% \mathrm{NaCl}$ and $20 \mathrm{wt} \% \mathrm{NaCl}$. In case of Elastosil 2030, we observed that type of conductive solution does not influence the breakdown. However, in case of Kapton tape and Elastosil 2030 bonded together we are restrained from concluding whether type of liquid electrode has any influence on breakdown voltage, since due to instrumentation limit in large number of measurements breakdown is not detected. Experiments are performed to produce creasing instabilities and detect the onset voltage at which these instabilities occur. Creases are detected with both $3.5 \mathrm{wt} \% \mathrm{NaCl}$ and $20 \mathrm{wt} \% \mathrm{NaCl}$ conductive solutions used as top electrode. We demonstrate that creasing deformation at the onset voltage changes the capacitance of the DE. At the beginning when voltage is applied, the film is in the flat state and there is no change in the capacitance. However, when certain value of voltage is reached the surface starts to deform and influences change of the capacitance. Further experiments will be performed with attached stiff biofouling layer on the surface of the silicone layer. 
When stiff biofouling material is attached to the surface of the silicone elastomer, the threshold voltage necessary to develop the creases on the surface of the silicone increases. Measuring the capacitance versus voltage enables identification of the voltage threshold, and therefore monitoring of biofouling growth.

\section{Acknowledgements}

Financial support for the project from the Hempel Foundation to CoaST (The Hempel Foundation Coatings Science and Technology Centre) is acknowledged. S. Krpovic had financial support from Otto Mønsted Fond and DTU Idella Foundation during her external stay at Auckland Bioengineering Institute, The University of Auckland.

\section{References}

[1] Nurioglu, A. G., Esteves, A. C. C. and De With, G., "Non-toxic, non-biocide-release antifouling coatings based on molecular structure design for marine applications,” J. Mater. Chem. B 3(32), 6547-6570 (2015).

[2] Jin, H., Zhang, T., Bing, W., Dong, S. and Tian, L., "Antifouling performance and mechanism of elastic graphenesilicone rubber composite membranes,” J. Mater. Chem. B 7(3), 488-497 (2019).

[3] Chambers, L. D., Stokes, K. R., Walsh, F. C. and Wood, R. J. K., "Modern approaches to marine antifouling coatings,” Surf. Coatings Technol. 201(6), 3642-3652 (2006).

[4] Bixler, G. D. and Bhushan, B., "Review article: Biofouling: Lessons from nature,” Philos. Trans. R. Soc. A Math. Phys. Eng. Sci. 370(1967), 2381-2417 (2012).

[5] Thorlaksen, P., Yebra, D. M. and Catala, P., "Hydrogel Based Third Generation Fouling Release Coatings,” Gall. Mag. 5, 218-224 (2007).

[6] Telegdi, J., Trif, L. and Románszki, L., “Smart anti-biofouling composite coatings for naval applications,” Smart Compos. Coatings Membr. Transp. Struct. Environ. Energy Appl., 123-155 (2016).

[7] Magin, C. M., Cooper, S. P. and Brennan, A. B., "Non-toxic antifouling strategies," Mater. Today 13(4), 36-44 (2010).

[8] Shivapooja, P., “Active Surface Deformation Technology for Management of Marine Biofouling” Doctoral dissertation, Duke University (2016).

[9] Scardino, A., De Nys, R., Ison, O., O’Connor, W. and Steinberg, P., “Microtopography and antifouling properties of the shell surface of the bivalve molluscs Mytilus galloprovincialis and Pinctada imbricata," Biofouling 19(Supplement), 221-230 (2003).

[10] O’Neill, P., Barrett, A., Sullivan, T., Regan, F. and Brabazon, D., "Rapid Prototyped Biomimetic Antifouling Surfaces for Marine Applications,” Mater. Today Proc. 3(2), 527-532 (2016).

[11] Wang, Q. and Zhao, X., “Creasing-wrinkling transition in elastomer films under electric fields," Phys. Rev. E Stat. Nonlinear, Soft Matter Phys. 88(4), 1-6 (2013).

[12] Zhao, X. and Wang, Q., "Harnessing large deformation and instabilities of soft dielectrics: Theory, experiment, and application,” Appl. Phys. Rev. 1(2) (2014).

[13] Hong, W., Zhao, X. and Suo, Z., "Formation of creases on the surfaces of elastomers and gels," Appl. Phys. Lett. 95(11), 2007-2010 (2009).

[14] Zhao, X. and Suo, Z., “Electrostriction in elastic dielectrics undergoing large deformation,” J. Appl. Phys. 104(12) (2008).

[15] Weiss, F., Cai, S., Hu, Y., Kyoo Kang, M., Huang, R. and Suo, Z., "Creases and wrinkles on the surface of a swollen gel,” J. Appl. Phys. 114(7) (2013).

[16] Wang, Q., Zhang, L. and Zhao, X., "Creasing to cratering instability in polymers under ultrahigh electric fields," Phys. Rev. Lett. 106(11), 1-4 (2011).

[17] Wang, Q., Tahir, M., Zhang, L. and Zhao, X., "Electro-creasing instability in deformed polymers: Experiment and theory,” Soft Matter 7(14), 6583-6589 (2011).

[18] Shivapooja, P., Wang, Q., Orihuela, B., Rittschof, D., Lõpez, G. P. and Zhao, X., "Bioinspired surfaces with dynamic topography for active control of biofouling,” Adv. Mater. 25(10), 1430-1434 (2013).

[19] Zhang, L., Wang, Q. and Zhao, X., "Mechanical constraints enhance electrical energy densities of soft dielectrics," Appl. Phys. Lett. 99(17) (2011).

[20] Suo, Z., “Theory of dielectric elastomers,” Acta Mech. Solida Sin. 23(6), 549-578 (2010).

[21] Yu, L. and Skov, A. L., "Molecular Strategies for Improved Dielectric Elastomer Electrical Breakdown Strengths," Macromol. Rapid Commun. 39(16), 1-6 (2018). 
[22] Technical Data Sheet., “Elastosil ${ }^{\circledR}$ Film 2030 250/50” (2018).

[23] Vaicekauskaite, J., Mazurek, P., Vudayagiri, S. and Skov, A. L., "Mapping the mechanical and electrical properties of commercial silicone elastomer formulations for stretchable transducers," J. Mater. Chem. C 8(4), 1273-1279 (2020).

[24] Zhao, R., Lin, S., Yuk, H. and Zhao, X., "Kirigami enhances film adhesion,” Soft Matter 14(13), 2515-2525 (2018).

[25] Zakaria, S., Madsen, F. B. and Skov, A. L., "Post Curing as an Effective Means of Ensuring the Long-term Reliability of PDMS Thin Films for Dielectric Elastomer Applications,” Polym. - Plast. Technol. Eng. 56(1), 8395 (2017). 


\section{Supplementary material}

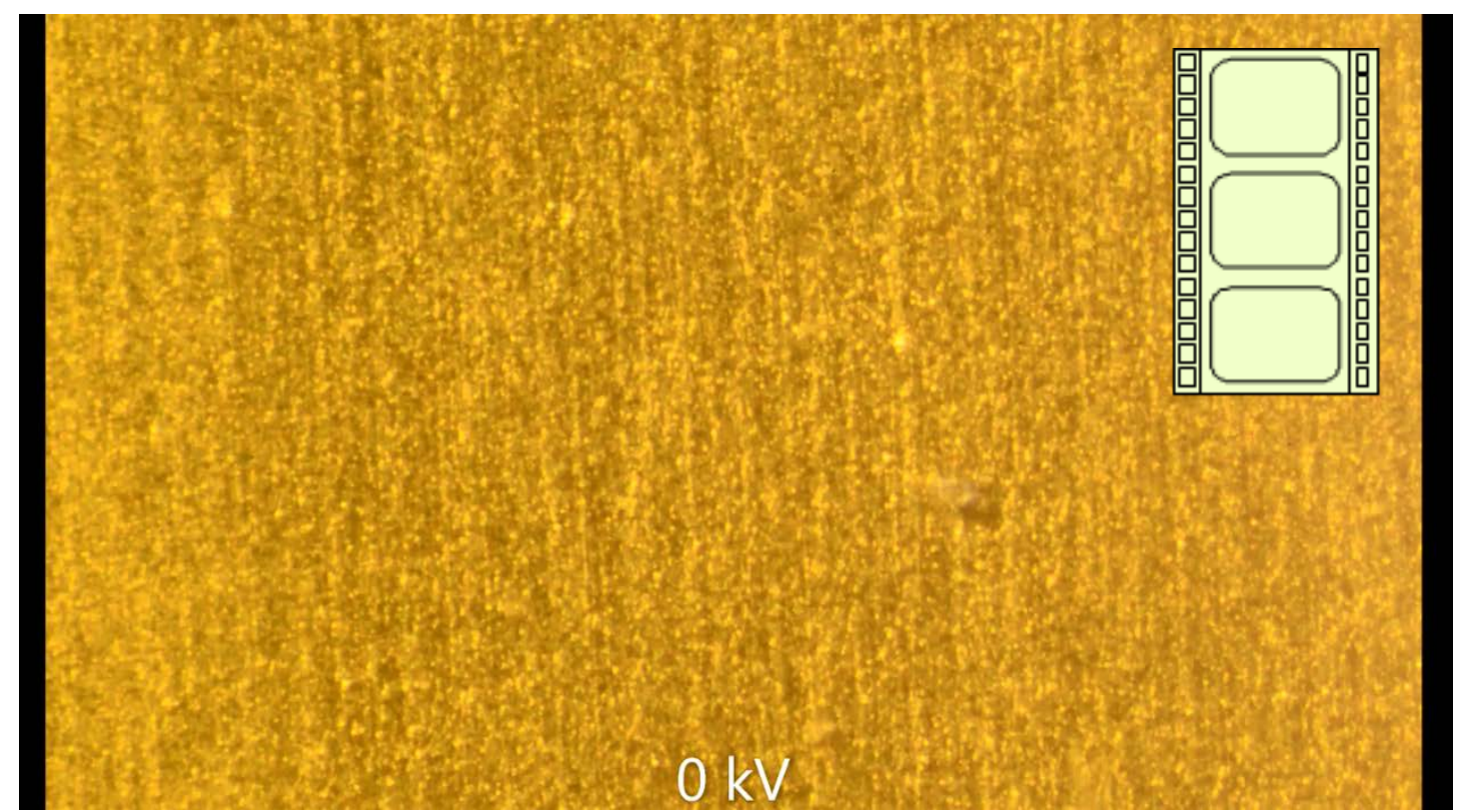

Video 1. Video illustrates creasing deformation of the top surface of the Ecoflex 00-30 membrane. Images showing state when there are no creases at the top surface (no voltage applied) and state when creases appear at the top surface (e.g. voltage of $4 \mathrm{kV}$ is applied) are connected in the video. http://dx.doi.org/10.1117/12.2558402.1 